Follow up after initial screening should also have been determined on the basis of ethnic origin and closeness of contact. However, we found that ethnic origin was not routinely recorded and contacts were not clearly classified as close or casual (apart from name and address).

\section{BRITISH THORACIC SOCIETY GUIDELINES}

The British Thoracic Society continues to recommend follow up of close contacts (those unvaccinated with Heaf grade 2 and all with Heaf grade 3-4) for up to two years. ${ }^{2}$ In our study all five asymptomatic contacts with tuberculosis had it diagnosed on initial screening, at which time the decision to give chemoprophylaxis to another four contacts was made. In the light of these results and similar low yields from other contact studies $^{3-5}$ prolonged follow up seems to be unnecessary in districts like South Glamorgan with small immigrant populations.

The $1978,{ }^{1} 1983,{ }^{6}$ and $1990^{2}$ British Thoracic Society guidelines recommend screening casual contacts only if the index patient is highly infectious, yet the term is undefined. If "highly infectious index case" were to be defined as an index patient who had at least one close contact with tuberculosis diagnosed then the casua contacts of $94 \%$ of index patients need not have been screened. This would have meant 253 fewer contacts being screened, resulting in 184 fewer Heaf tests and 151 fewer chest radiographs. This would have saved the health authority $£ 6000-£ 8000$ in direct costs alone (Heaf tests and radiographs). Time and effort spent on tracing contacts would have been cut, together with the administrative work of maintaining records, filing results, and sending clinic appointments. Over 300 clinic attendances could have been avoided, thus reducing the contact clinic schedule by around 15 sessions and allowing redeployment of the contact team to other community health service activities.

\section{IMPROVING PERFORMANCE}

We recommend that to improve the efficiency of tuberculosis contact tracing the notification form should specify the smear test result and ethnic origin of the index patient. Classification of contacts into close or casual should be clearly recorded by the contact team. Screening can then be cost effectively focused on those at greatest risk of developing tuberculosis.

In the light of the results of this study changes incorporating the above recommendations have been made in the contact tracing procedure in South Glamorgan. A further retrospective study is planned in two years time to evaluate these changes in practice and thus complete the audit feedback loop.

\footnotetext{
1 British Thoracic and Tuberculosis Association. A study of a standardized contact procedure in tuberculosis. Tubercle 1978;59:245-59.

2 Subcommitree of the Joint Tuberculosis Commitree of the British Thoracic Socity. Contol and prevention of uberculosis Britain: Brish Thoracic Society. Control and prevention of

3 Spencer Jones J. Tuberculosis case finding in coastal south-east Kent, 1977-81. Lancet 1983; ; $232-3$.

4 Selby $\mathrm{CD}$, Allen $\mathrm{MB}$, Leitch AG. Tuberculosis contact tracing in Edinburgh. Thorax 1988;43:834P.

5 Esmonde TFG, Petheram IS. Audit of tuberculosis contact tracing procedure in South Gwent. Respir Med 1991;85:421-4.

6 Joint Tuberculosis Committee. Control and prevention of tuberculosis: a code of practice. BMF 1983;287:1118-21.

(Accepled 24 February 1992)
}

\title{
Must diabetes be a fatal disease in Africa? Study of costs of treatment
}

\author{
Stella S Chale, Andrew B M Swai, Phare G M Mujinja, Donald G McLarty
}

Department of Medicine, Muhimbili Medical Centre, PO Box 65001, Dar es Salaam, Tanzania Stella S Chale, lecturer in medicine

Andrew B M Swai, senior lecturer in medicine Donald G McLarty, professor of medicine

Department of Behavioural Sciences, Muhimbili Medical Centre, Dar es Salaam, Tanzania

Phare G M Mujinja, lecturer in health economics

Correspondence to: Dr Chale.

$B M \mathcal{F}$ 1992;304:1215-8

\section{Abstract}

Objective-To estimate the costs of diagnosis and treatment of diabetes in Tanzania.

Design-Costs estimated from the reported and recorded experience of patients with newly presenting diabetes in 1989-90 and of diabetic patients first seen in 1981-2.

Setting-Muhimbili Medical Centre, Dar es Salaam.

Subjects -464 patients ( 315 men and 149 women). 262 patients diagnosed during 1 September 1989-31 August 1990 (group 1) and 202 during 1 June 1981-31 August 1982 (group 2).

Results - The average annual direct cost of diabetes care in $1989-90$ was $\$ 287$ for a patient requiring insulin and $\$ 103$ for a patient not requiring insulin. Purchase of insulin accounted for $68.2 \%(\$ 156)$ of the average annual outpatient costs for patients requiring insulin. For patients not requiring insulin the cost of oral hypoglycaemic drugs and treatment of chronic complications and infections accounted for $42.5 \%(\$ 29.3)$ and $48.8 \%(\$ 33.7)$ of costs respectively. Cost of outpatient care of diabetic patients for the whole of Tanzania was estimated at $\$ 2.7 \mathrm{~m}, \$ 875128$ $(32.2 \%)$ of which was for insulin. Doctors' and nurses' costs accounted for $\mathbf{0 . 2} \%$ of total costs of outpatient care. The annual direct inpatient care costs were estimated at $\$ 1 \cdot 25 \mathrm{~m}$. Around $0.2 \%$ of the Tanzanian population aged 15 years and over used the equivalent of $8 \%$ of the total government health expenditure, which was $\$ 47408382$.

Conclusion-Diabetes places a severe strain on the limited resources of developing countries. If
African patients with diabetes have to pay for their treatment most will be unable to do so and will die.

\section{Introduction}

People with diabetes mellitus are known to be heavy lifetime users of health care resources, ${ }^{1-4}$ but few studies have considered the economic implications of this for developing countries. ${ }^{15}$ Tanzania (population 23174336 ), with a gross per capita income of US $\$ 160$ to $\$ 200$ per year, is one of the world's 25 poorest countries. Health expenditure per head has fallen from $\$ 7$ in 1980 to $\$ 2$ in 1989 .

Rates of non-infectious diseases such as diabetes in rural Tanzania are among the lowest in the world, ${ }^{78}$ but chronic, non-infectious diseases consume a high proportion of the total health expenditure. The present study was undertaken to estimate the direct and indirect costs of diagnosis, treatment, complications, and follow up of diabetic patients in Dar es Salaam, Tanzania, and from these to estimate the costs of diabetes nationally.

\section{Subjects and methods}

Dar es Salaam is Tanzania's largest city with a population of 1.5 million. Most African patients with diabetes from the city are referred to Muhimbili Medical Centre, the country's largest hospital. Patients who need inpatient care are admitted to the general medical wards, where they are seen and instructed by nurses with special training in diabetes.

Special diabetic outpatient clinics are held every 
Thursday morning and afternoon. Patients are given three monthly appointments but may attend weekly if necessary. Glycaemic control is assessed by urine testing, the aim being to keep the urine glucose free. Blood glucose is measured at the clinic in patients with poor control. All patients attending government health facilities in Tanzania are provided with free medical care. Insulin, needles, syringes, oral hypoglycaemic drugs, and dipsticks for measuring urine glucose concentration are therefore issued free of charge depending on availability. If any item is not available patients have to buy it from private pharmacies.

We studied two groups of diabetic patients for cost analysis: Group 1 comprised 262 consecutive newly presenting diabetic patients ( 179 men, 83 women) seen at the diabetic clinic and in all wards of our hospital between 1 September 1989 and 31 August 1990. Thirty two patients required insulin, 222 did not require insulin, and eight had diabetes of uncertain type. ${ }^{9}$ Nine patients died at time of presentation or during follow up. Group 2 comprised 202 patients (136 men, 66 women) who had newly presented between 1 June 1981 and 31 May 1982. At that time 60 patients required insulin, 102 did not require insulin, and 40 had diabetes of uncertain type. Of the 202 patients, 78 were still alive and attending the clinic; 57 were known to have died and a further 67 had not attended the clinic for over a year. The mean age at death was 43 years, with a mean duration of diabetes at death of 23 (median 5 , range 1-96) months.

The mean age of onset of diabetes in patients requiring insulin in both groups was 37 (range 5-75) years and in patients not requiring insulin 46 (21-78) years.

Questionnaires were completed for each patient. The first part, completed only for patients in group 1, recorded information on socioeconomic status, costs incurred from the onset of symptoms until time of diagnosis of diabetes, the number and type of health facilities visited, time spent and transport costs for each visit, and the costs of investigations and prescribed treatments.

Part 2 of the questionnaire was completed for patients in both groups. Information was obtained on the cost of follow up after diabetes had been diagnosed, time spent and transport charges per visit to the diabetic clinic, and the frequency of and time spent on self injection with insulin. Information was also obtained from the patients' files on the number of follow up visits per year and documented complications. The numbers of hospital admissions and deaths were also noted. Patients in both groups of patients were followed up until October 1990.

\section{ESTIMATING COSTS}

The costs of hypoglycaemic drugs, insulin, syringes, spirit, cotton wool, and urine dipsticks for monitoring glucose concentrations prescribed and any other documented drugs or treatments were calculated from 1989-90 prices charged by the government central medical stores and estimates of the hospital's budget. The market prices charged by the pharmacies in the city were used for supplies such as urine dipsticks which were not regularly available at the hospital and which patients had to buy. The costs of treatment and investigations at private hospitals were calculated according to prices charged by the various private hospitals in the city.

We assumed that patients with diabetes requiring insulin used one syringe and a needle for one week (though some used them much longer) and used spirit and a swab before each injection (though not all did so); that patients requiring insulin monitored their urine for glucose once a day and patients not requiring insulin twice a week; and that at each visit to the diabetic clinic urine was tested for glucose in all patients and all patients received the drugs prescribed in sufficient amounts to last until the next visit, usually three months.

In estimating the direct costs of staff it was assumed that: a doctor spent 7 minutes with each patient at the diabetic clinic at each visit and 10 minutes with each admitted diabetic patient daily; nurses spent 10 minutes with an outpatient and 90 minutes for an inpatient daily; and the average salary was $\$ 0.3$ per working hour for a doctor and $\$ 0.04$ per working hour for a nurse.

Costs of complications included costs of treating infections and costs of the chronic complications, particularly amputations, disabling paraesthesia, cataract extraction, treatment of hypertension, and congestive cardiac failure.

Calculations of the direct costs of caring for all diabetic patients in Tanzania aged 15 years and over were based on a prevalence of $0.2 \%$ for diabetic patients aged 15 years or more requiring insulin or ora hypoglycaemic drugs; this figure was derived from previous studies. ${ }^{79}$

Data were analysed with the statistical package SPSS. The $\chi^{2}$ test and the Mann-Whitney test were used for comparisons between groups.

\section{Results}

Patients in group 1 made an average of 3.8 (median 3 , range 1-50) visits to health units before diabetes was diagnosed. The mean number of recorded follow up visits to the diabetic clinic per year in group 2 patients was 3.0 for patients requiring insulin and 2.3 for patients not requiring insulin. (These figures exclude many attendances at the clinic without appointments for renewal of prescriptions and complications).

Acute metabolic complications (hypoglycaemia and diabetic ketoacidosis) were the reason for admission in $60 \cdot 3 \%$ (143 of 237) of those patients admitted at least once. Of the 262 patients in group 1, $64(24 \%)$ were admitted once and $17(6 \%)$ on two or more occasions during follow up. Most admissions were of patients requiring insulin. Of the 202 patients diagnosed in $1981-2$, only $46(23 \%)$ had not been admitted during the eight years of follow up. Ninety eight $(49 \%)$ had been admitted once, $31(15 \%)$ twice, $12(6 \%)$ thrice, and $15(7 \%)$ on four or more occasions. The mean duration of admission for all patients in group 2 was 34 (median 21, range 1-234) days.

For a diabetic patient requiring insulin the total annual outpatient costs were $\$ 229$ compared with $\$ 69$ for a diabetic patient not requiring insulin. For 。 patients requiring insulin $68.2 \%$ of the annual out- $\frac{7}{0}$ patient costs were $(\$ 156$ of $\$ 229)$ for provision of insulin. For patients with non-insulin dependent $\widetilde{O}$ diabetes $42.5 \%$ (\$29.3) of total outpatient costs $(\$ 69 \cdot 0)$ were spent on the provision of oral hypoglycaemic drugs and $48 \cdot 8 \%(\$ 33 \cdot 7$ ) on treatment of complications. However, the average cost per patient of treating infections and complications in 119 patients with these problems was $\$ 91 \cdot 2$. Nurses' and doctors' costs amounted to only $0 \cdot 2 \%(\$ 0 \cdot 2)$ of the total outpatient costs. For inpatients, nurses' and doctors' costs accounted for $11.6 \%(\$ 7.9)$ of total costs. Meals $\mathbb{D}$ and bed accounted for $22 \%(\$ 15 \cdot 1)$ of total costs and investigations for $40 \cdot 4 \%(\$ 27 \cdot 4)$

The table shows the one year costs of diabetes care for both inpatients and outpatients at a national level estimated from the direct costs of diabetes in patients in groups 1 and 2 listed above. Almost one third $(\$ 875128)$ of the total outpatient costs $(\$ 2721151)$ were for purchase of insulin and $24 \cdot 3 \%$ (\$661 641) for purchase of oral hypoglycaemic drugs. Treatment of 
TABLE I-Estimated one year costs (US\$) of outpatient and inpatient care of all diabetic patients in Tanzania in 1989-90

\begin{tabular}{lrr}
\hline & $\begin{array}{c}\text { Average costs } \\
\text { US } \$\end{array}$ & $\begin{array}{r}\text { Of total } \\
\text { costs }\end{array}$ \\
\hline Outpatient costs: & 32429 & $1 \cdot 2$ \\
Transport & 1423 & $0 \cdot 1$ \\
Clinic nursing costs & 2571 & $0 \cdot 1$ \\
Clinic doctors' costs & 51177 & $1 \cdot 9$ \\
Clinic urine and blood glucose tests & 95974 & $3 \cdot 5$ \\
Self care urine dipsticks & 119250 & $4 \cdot 4$ \\
Self care spirit and cotton wool & 42166 & $1 \cdot 5$ \\
Self care syringes and needles & 875128 & $32 \cdot 2$ \\
Insulin & 661641 & $24 \cdot 3$ \\
Oral hypoglycaemic drugs & 839392 & $30 \cdot 8$ \\
Treatment of complications & 2721151 & $100 \cdot 0$ \\
\hline Total outpatient costs & & \\
& & \\
Inpatient costs: & 507377 & $40 \cdot 4$ \\
Investigations & 6854 & $0 \cdot 5$ \\
Oral hypoglycaemic drugs & 74350 & $5 \cdot 9$ \\
Insulin & 45886 & $3 \cdot 7$ \\
Antibiotics & 18001 & $1 \cdot 4$ \\
Antihypertensive drugs & 56082 & $4 \cdot 5$ \\
Intravenous fluids & 63450 & $5 \cdot 1$ \\
Syringes and needles & 60755 & $4 \cdot 8$ \\
Other treatment & 275896 & $22 \cdot 0$ \\
Meal and bed & 114810 & $9 \cdot 1$ \\
Nursing costs & 31851 & $2 \cdot 5$ \\
Doctors' costs & 1255312 & $100 \cdot 0$ \\
\hline Total inpatient costs & & \\
\hline
\end{tabular}

complications accounted for a further $30 \cdot 8 \%(\$ 839392)$ of total outpatient costs.

\section{Discussion}

In several sub-Saharan African countries where patients are required to pay for medical services diabetes, especially insulin dependent diabetes, is regarded as a fatal disease. For patients living in countries like Tanzania where, so far, medicines are provided free of charge the prognosis for diabetic patients is brighter. Now, however, faced with severe economic difficulties, underfunding of basic social services, lower producer prices, high debt servicing payments, low wages, high inflation, and shortage of foreign exchange the days of free medical care in Tanzania may be numbered. If patients with chronic diseases such as diabetes are not exempt from payment it will be impossible for most patients to meet the cost of insulin and oral hypoglycaemic drugs. The average per capita income in Tanzania ranges from $\$ 160$ to $\$ 200$ per year and an insulin dependent patient requires $\$ 156$ for purchase of insulin alone. The future for diabetic patients in most sub-Saharan countries therefore looks bleak unless new ways are found of financing health care or governments devote a larger proportion of their gross national product to health care. Government expenditure on health care in Tanzania in 1989-90 was $\$ 47408382$, which represents $2.7 \%$ of gross national product compared with $11 \%$ in the United States and $6.2 \%$ in Britain. ${ }^{10}$ Per capita expenditure on health has fallen from $\$ 7$ in 1980 to $\$ 2$ in 1990 compared with $\$ 1075$ in 1980 in the United States. ${ }^{11}$

\section{PROBLEMS OF ESTIMATING COSTS}

The limitations and assumptions made in estimating the direct and indirect costs of diabetes in the two groups of patients in Dar es Salaam and the extrapolation of our findings to national level should be acknowledged. To estimate cost of diabetes care we had to rely on patients' records and memories and our experience of the management of diabetes in various situations. It was often difficult to obtain the exact prices of drugs and services from private pharmacies and hospitals and from the government central medical stores. Lack of price controls in the private sector also causes great fluctuations in market prices. The price of a $5 \mathrm{mg}$ tablet of glipizide varied in private pharmacies from 5 to 70 Tanzanian shillings. Prices used in this study were therefore almost certainly lower than current market values.

The assumption was also made that drugs were always available, which is often not so. Water and electricity costs were not included in calculation of inpatient costs. Nor were costs borne by the patients' families during hospital admission. It should also be noted that government is not the sole source of health care funding. Voluntary agencies such as church hospitals make a large contribution to health care.

With such constraints in mind this study has shown that even in countries with low rates of diabetes, diabetes care places extensive demands on national health budgets. Direct costs of almost $\$ 4$ million may be small compared with the $£ 484$ million spent on diabetes care in England and Wales in 1986-7, ${ }^{1}$ but nevertheless represent almost $8 \%$ of the total government health budget. In the United Kingdom it is estimated that people with diabetes consume $4-5 \%$ of health care resources. ${ }^{1}$ This is comparable with the situation in the United States, where diabetes care consumed almost $5 \%$ of $\$ 500$ bn spent on overall health care in $1987 .{ }^{2}$

Calculation of indirect costs is also difficult in developing countries. We have previously shown that the five year survival rates for patients with diabetes requiring insulin and not requiring insulin were $71 \%$ (95\% confidence interval $62 \%$ to $80 \%)$ and $84 \%(80 \%$ to $89 \%$ ) respectively. ${ }^{12}$ The complications of diabetes also account for a large proportion of indirect costs. It was noteworthy that $30 \%$ of newly presenting patients in group 1 had evidence of one or more complications at the time of presentation.

\section{COMPARISON WITH OTHER DEVELOPING COUNTRIES}

To our knowledge a study from Guam in 1976 is the only published report on the total economic burden of diabetes in a developing country. ${ }^{5}$ A study from Malawi suggested that the cost of treating diabetic patients will be dominated by their need for insulin and oral hypoglycaemic drugs. For insulin treated patients the cost was estimated to be $\$ 100$ a year. ${ }^{5}$

We also found that insulin dominated the costs of diabetes. Of the $\$ 229$ required each year to care for one diabetic outpatient requiring insulin, $\$ 156(68 \%)$ was required to buy insulin. In Malawi estimates of the cost of one year's supply of oral hypoglycaemic drugs was about $\$ 25$, which compares with our estimate of $\$ 33$ considering the time interval between the two estimates.

\section{REDUCING THE BURDEN}

Can costs be reduced? At the time of diagnosis $30 \%$ of patients in group 1 had one of the chronic complications of diabetes, and before diabetes was diagnosed patients had to make an average of 3.8 visits to health units. In many patients infection precipitated the symptoms of diabetes and often patients had received antibiotics and antimalarial drugs for many days. In addition, some patients had attended several institutions before diagnosis. These observations point to the continuing need for education of both health workers and the general public on the symptoms of diabetes. Delay in diagnosis increases direct and indirect costs. Little can be done to limit the cost of insulin and oral hypoglycaemic drugs, but careful consideration should be given to the patient's need for insulin. High rates of insulin use have been reported in several studies from Africa, ${ }^{1314}$ and we wonder how many patients receive insulin unnecessarily.

Treatment of complications accounted for the second highest proportion of total direct outpatient costs. Many of these complications could be avoided by better patient education and improved control of 
diabetes. Most patients have no means of assessing control apart from the presence or absence of symptoms. Home monitoring of blood glucose concentrations is economically impracticable for most patients, but easier access to urine dipsticks would probably increase patients' interest and motivation in improved control and would not add greatly to total direct costs.

The need for inpatient admission should also be considered carefully, especially for newly presenting patients. Wherever possible admission is best avoided if the patient and family are able to receive initial daily outpatient education and supervision. ${ }^{15}$ Patients should be admitted only if they require nursing care or circumstances do not permit easy attendance at outpatient clinics. Admission rates for diabetic patients in Tanzania are six times higher than in the general population. ${ }^{16}$ When patients are admitted careful consideration should be given to the need for investigations. Testing urine four times or more daily for example, may be unnecessary if blood glucose concentrations are also being measured. Consideration should also be given to the period of admission since patients are often kept in the wards until most urine results are glucose free.

The small proportion of direct costs due to nurses' and doctors' services reflects the low rates of pay of medical staff in most sub-Saharan countries. A lecturer in medicine, for example, is paid $\$ 60$ monthly. The reasons for such low rate of remuneration are understood, but attention must also be paid to this problem since the motivation and interest of those caring for patients can have a significant impact on the quality of care.
We thank the director general, colleagues, and staff, of Muhimbili Medical Centre; Professor K G M M Alberti, University of Newcastle upon Tyne; the Ministry of Health, United Republic of Tanzania; the British Council; and the Overseas Development Administration.

1 Laing W, Williams R. Diabetes: a model for health care management. London: Office of Health Economics, 1989:32-49.

2 Fox NA, Jacobs J. Direct and indirect costs of diabetes in the United States in 1987. Alexandria, Virginia: American Diabetes Association, 1988.

3 Johnson B. Diabetes - the cost of illness and the cost of control. An estimate for Sweden 1978. Acta Med Scand 1983;671(suppl):19-27.

4 Triomphe A, Flori YA, Costagliola D, Eshchwege E. The cost of diabetes in France. Health Policy 1988;9:39-48.

5 Vaughan P, Gilson L, Mills A. Diabetes in developing countries: its importance for public health. Health Policy and Planning 1989; 4:97-109.

6 World Bank. United Republic of Tanzania: population, health and nutrition sector review, 1989. Washington, DC: World Bank, 1989.

7 McLarty DG, Swai ABM, Kitange HM, Masuki G, Mtinangi BL, Kilima PM, et al. Prevalence of diabetes and impaired glucose tolerance in rural Tanzania. Lancet 1989;i:871-5.

8 World Health Organisation. World Health Organisation supports world diabetes day. WHO Features 1991 ; No 158 (June): 1-4.

9 Swai ABM . Luta J, McLarty DG. Diabetes in tropical Africa: a prospective study, 1981-7. Characteristics of newly presenting patients in Dar es Salaam, study, 1981-7. Characteristics of

10 Aaron H, Schwartz WB. Rationing health care: the choice before us. Science 1990;247:418-22.

11 Enthoven A. Reforming US health care: the consumer choice health plan. In: Black N, Boswell D, Gray A, Murphy S, Popay J, eds. Health and disease. Milton Keynes: Open University Press, 1984: 335-40.

12 McLarty DG, Kinabo L, Sawi ABM. Diabetes in tropical Africa: a prospective study, 1981-7. II. Course and prognosis. BMF 1990;300:1107-10.

13 Corrigan CB, Ahren B. Ten years' experience of a diabetes clinic in Northern Tanzania. East Afr Med f 1987;64:772-80.

14 Rolfe M, Armstrong JRM. Diabetes mellitus on the Zambian Copperbelt. f R Coll Phys Lond 1989;23:255-9.

15 Scott RS, Brown LJ, Clifford P. Use of health services by diabetic persons. II Hospital admissions. Diabetes Care 1985;8:43-7.

16 Planning Commission. Hali ya Uchumi wa taifa katika Mwaka 1989. Dar es Salaam: Planning Commission, President's Office, 1990.

(Accepted 24 February 1992)

\title{
Hyponatraemia and death or permanent brain damage in healthy children
}

\author{
Allen I Arieff; J Carlos Ayus, Cosmo L Fraser
}

\section{Abstract}

Objective-To determine if hyponatraemia causes permanent brain damage in healthy children and, if so, if the disorder is primarily limited to females, as occurs in adults.

Design-Prospective clinical case study of 16 affected children and a review of 24412 consecutive surgical admissions at one medical centre.

Patients - 16 children (nine male, seven female; age 7 (SD 5) years) with generally minor illness were electively hospitalised for primary care. Consultation was obtained for the combination of respiratory arrest with symptomatic hyponatraemia (serum sodium concentration $\leq 128 \mathrm{mmol} / \mathrm{l}$ )

Main outcome measures-Presence, gender dis-

University of California School of Medicine, San Francisco, California Allen I Arieff, professor of medicine

Cosmo L Fraser, associate professor of medicine

\section{Baylor College of} Medicine, Houston, Texas $\mathrm{J}$ Carlos Ayus, professor of medicine

Correspondence to: Professor Allen I Arieff, Department of Medicine, Veterans Affairs Medical Center $(111 \mathrm{G})$, San Francisco, CA 94121, USA.

BMF 1992;304:1218-22 cerebral oedema detected at either radiological or postmortem examination. All 15 patients not treated for their hyponatraemia in a timely manner either died or were permanently incapacitated by brain damage. The only patient treated in a timely manner was alive but mentally retarded.

Conclusions-Symptomatic hyponatraemia can result in a high morbidity in children of both genders, which is due in large part to inadequate brain adaptation and lack of timely treatment.

\section{Introduction}

In previous studies from our laboratories we have described the symptomatology, clinical course, effects of treatment, and pathological findings in more than 225 adults (aged over 16) with symptomatic hyponatraemia..$^{1-8}$ Although the actual incidence of hyponatraemia seems to be similar among men and women ${ }^{89}$ almost all adult patients suffering hyponatraemic brain damage are women. Although there are a number of reported paediatric cases of hyponatraemia, ${ }^{10-12}$ there are few reported cases of death or permanent brain damage among children with this disorder, ${ }^{13}{ }^{14}$ and most such children had pre-existing neurological disorders. ${ }^{15-17}$ Neither the gender distribution nor the incidence of brain damage among children with hyponatraemia is known. ${ }^{10} 12-17$ Among children suffering brain damage from hyponatraemia neither the type nor the gender distribution is known. We describe both a prospective and a retrospective analysis of generally healthy children who were elect- 